\title{
Um olhar quanti-qualitativo sobre o efeito da variável tempo de exposição em fenômenos de acomodação dialetal
}

Rubens Marques de Lucena ${ }^{a}$

\begin{abstract}
Resumo
Este artigo tem como objetivo oferecer uma visão de conjunto a respeito de três trabalhos de contato dialetal realizados no nordeste do Brasil, discutindo a relevância da variável tempo de exposição/tempo de residência nos processos de acomodação dialetal. As pesquisas foram realizadas entre 2013 e 2015 na Universidade Federal da Paraíba e são resultados de dissertações de Mestrado concluídas no Programa de Pós-Graduação em Linguística. Apesar de enfatizarem a análise da acomodação dialetal do ponto de vista quantitativo, a partir de uma proposta teórico-metodológica laboviana, salientamos aqui a necessidade de um olhar mais qualitativo, com ênfase nas atitudes linguísticas dos falantes. Concluimos, portanto, que apesar de a variável tempo de exposição exercer uma influência no processo de acomodação dialetal, ela necessita de um gatilho para o seu funcionamento: a presença de atitudes linguísticas favoráveis com relação ao novo dialeto a ser adquirido.
\end{abstract}

Palavras-chave: Teoria e análise linguística. Contato dialetal. Teoria da acomodação dialetal. 


\section{Introdução}

Embora os estudos a respeito da acomodação dialetal sejam numerosos no panorama acadêmico internacional, ainda há poucos trabalhos no que se refere a esse processo nos dialetos brasileiros, sobretudo com relação aos falares do nordeste do Brasil. Nesse sentido, este artigo tem um duplo objetivo: 1) primeiramente, oferecer uma visão de conjunto no que se refere a três trabalhos de acomodação dialetal realizados no nordeste do Brasil (envolvendo, especificamente, o dialeto do português brasileiro falado na cidade de João Pessoa); 2) em segundo lugar, discutir a relevância da variável tempo de exposição/tempo de residência nessas pesquisas, que parece exercer um papel importante nos processos de acomodação dialetal.

Os três trabalhos foram realizados entre 2013 e 2015 na Universidade Federal da Paraíba e são resultados de dissertações de Mestrado concluídas no Programa de PósGraduação em Linguística daquela universidade. Apesar de as três pesquisas enfatizarem a análise da acomodação dialetal do ponto de vista quantitativo (a partir de uma proposta teóricometodológica laboviana), salientamos aqui a necessidade de um olhar mais qualitativo (com ênfase nas atitudes linguísticas dos falantes). De fato, como abordaremos mais adiante, acreditamos que a correta compreensão do processo de acomodação dialetal só acontece a partir do entendimento das atitudes linguísticas dos envolvidos no processo. De fato, em alguns momentos das pesquisas, só é possível compreender certos dados estatísticos a partir da fala dos envolvidos no fenômeno.

Os trabalhos aqui resenhados parecem apontar para uma conclusão interessante: a relevância da variável tempo de exposição/tempo de residência em processos de acomodação dialetal. No entanto, os dados qualitativos parecem indicar algo a mais: as atitudes/crenças positivas parecem ter um papel ainda mais importante, pois funcionam como gatilho para que a variável acima mencionada tenha pleno funcionamento. A primeira pesquisa versa sobre a acomodação linguística de falantes cabo-verdianos e guineenses em relação ao português brasileiro. Para esse propósito, foi analisada a vocalização da lateral [1] em coda silábica do português falado pelos africanos. Os outros dois trabalhos analisam dois fenômenos relacionados 
à fricativa [s] a partir de dois corpora distintos: brasileiros naturais de São Paulo que passaram a morar em João Pessoa e paraibanos que passaram a residir em Recife.

Começaremos este artigo com uma seção teórica a respeito da Teoria da Acomodação da Comunicação e sobre atitudes linguísticas, aportes teóricos que norteiam os trabalhos resenhados aqui. Dessa forma, pretendemos oferecer uma visão panorâmica dos resultados dos trabalhos, salientando os pontos de convergência entre eles. Nossos objetivos são apresentar alguns indicativos e mostrar as dificuldades que trabalhos dentro dessa perspectiva podem oferecer.

\section{Aporte teórico: Teoria da Acomodação da Comunicação e atitudes linguísticas}

Os primórdios da Teoria da Acomodação da Comunicação surgem a partir das primeiras publicações de Giles (1973) a respeito do que ele denominou de "Teoria da Acomodação da Fala". Nesse trabalho seminal, Giles critica alguns aspectos do paradigma laboviano, argumentando que o papel da formalidade-informalidade do contexto e o critério de "atenção à fala" (associados por Labov ao prestígio dos estilos de fala) poderiam ser interpretados como processos de acomodação interpessoal (cf. GILES; COUPLAND; COUPLAND, 1987).

Giles foca sua atenção para os fatores que estão envolvidos no processo de acomodação dialetal e para a influência de falantes sobre outros, fato que se exterioriza através do comportamento linguístico. Em outras palavras, a teoria propunha que a explicação através da "formalidadeinformalidade do contexto" poderia ser substituída por uma interpretação em termos de influência interpessoal, por meio da convergência linguística de um falante.

Em sua gênese, a teoria proposta por Giles (1973) tinha um foco sócio-psicológico, embora ela não tenha se restringido apenas a esse campo de estudo. Como afirma o autor, ao longo de doze anos a teoria se desenvolveu, levando em consideração os fenômenos relacionados aos processos de interação comunicativa. Assim, num segundo momento, a Teoria da Acomodação da Fala passou por uma releitura por parte de seus teóricos, numa perspectiva mais interdisciplinar, explorando aspectos linguísticos mais amplos, como as dimensões 
discursivas da interação social e fenômenos não verbais da língua. Surge, então, a Teoria da Acomodação da Comunicação, a partir do trabalho de Giles, Coupland e Coupland (1987).

De acordo com os autores, o indivíduo, com o objetivo de alcançar uma aceitação social, converge a sua maneira de falar à de seu interlocutor, processo denominado pelo autores de "convergência". Esse fenômeno se concretizaria a partir da adaptação de comportamentos linguísticos e extralinguísticos por parte do falante. Por outro lado, se o indivíduo evita uma aproximação do interlocutor, ele tende a realçar as diferenças dialetais que os separam, processo denominado pela teoria de "divergência".

Para Giles, Coupland e Coupland, a acomodação ocorrerá a depender das necessidades do falante. A teoria volta-se para as investigações de atitudes, motivações e estratégias usadas pelos indivíduos com o objetivo de atingir uma integração social e/ou preservar a identidade do grupo.

Atitudes são um dos muitos construtos hipotéticos utilizados nas ciências sociais. Como não é possível "observar" uma atitude, elas não são facilmente quantificadas, o que torna o seu estudo um pouco mais complicado. Para Rokeach (1974) e Lambert e Lambert (1975), o conceito de atitude apresenta uma estrutura tridimensional: a) uma dimensão cognitiva (pensamentos e crenças; conhecimento que tem uma pessoa acerca do que é verdadeiro/falso, desejável/indesejável); b) uma dimensão afetiva (sentimentos e emoções; posição positiva ou negativa a respeito do objeto da crença); e c) uma dimensão conativa (componente de conduta; predisposição de resposta que conduz a algum tipo de ação).

Cardoso se associa a esse pensamento, afirmando que

o caráter de relativa passividade que caracterizaria, de certa maneira, o componente cognitivo chegaria ao componente de conduta ativado pelo componente afetivo que, a partir das crenças, provoca reações determinadas, as quais, por sua vez, dão contornos para a ação final do indivíduo. (CARDOSO, 2015, p. 18)

Assim, a atitude deve ser encarada muito mais como um processo, dotado de certas etapas, e não simplesmente como um resultado. Esta é a maneira como as atitudes linguísticas são compreendidas nos três trabalhos resenhados neste artigo. Os trabalhos baseiam-se, portanto, no conceito de atitude apontado 
por Cardoso (2015) e nos aportes teóricos oferecidos pela Teoria da Acomodação da Comunicação. Não entraremos em detalhes a respeito dos procedimentos metodológicos de cada pesquisa; para isso, remetemos o leitor às suas versões originais.

\section{A lateral pós-vocálica em contato dialetal}

A primeira pesquisa a ser analisada neste artigo foi publicada em 2015. Intitulado "A lateral pós-vocálica em contato dialetal: um estudo com africanos lusófonos na Paraíba" (SILVA; LUCENA, 2015), o estudo investigou a lateral em posição de coda silábica, que é produzida de maneira vocalizada no português brasileiro, como em [aw'mosu] (almoço), e de maneira velarizada no português falado em Cabo Verde e na Guiné Bissau [ał'mosu].

O objetivo da pesquisa foi investigar se os guineenses e cabo-verdianos residentes em João Pessoa apresentavam indícios de acomodação linguística ao português brasileiro no que se refere à lateral em posição de coda silábica. Além disso, procurou-se identificar os fatores sociais e linguísticos que favoreciam essa acomodação (atitudes linguísticas).

Nesse sentido, foram selecionados 7 informantes, entre 20 e 30 anos, dos dois países africanos, residentes na cidade de João Pessoa (Brasil). Em ambos os países a língua oficial é a portuguesa e a variedade falada pelos africanos se assemelha à do português europeu.

A coleta de dados se deu por meio de entrevistas orais, divididas em quatro etapas: 1) uma "entrevista" sociolinguística nos moldes labovianos; 2) uma "entrevista" módulo língua (em que os informantes deveriam comentar sobre suas percepções acerca das diversas variedades da língua portuguesa com as quais têm contato); 3) uma leitura de textos; e 4) uma lista de palavras.

Foram controladas as seguintes variáveis: a) estilo (entrevista; leitura de textos; leitura de palavras); b) tempo de exposição (menos de 3 anos de residência no Brasil; entre 3 e 8 anos; mais de 8 anos); c) país de origem (Guiné Bissau; Cabo Verde); d) tonicidade da sílaba (lateral em posição tônica ['bolsa]; lateral em posição pretônica [cal'çada]; lateral em posição postônica ['fácil]); e) posição na palavra (sílaba inicial; 
medial; final); f) contexto fonológico anterior; g) contexto fonológico seguinte; e h) extensão do vocábulo.

Para a análise quantitativa dos dados, foi feito uso do software Goldvarb X (SANKOFF; TAGLIAMONTE; SMITH, 2005), utilizado em pesquisas variacionistas. Foi obtido um total de 1184 ocorrências da lateral pós-vocálica, distribuídas nas seguintes proporções:

Tabela 1. Resultado geral de ocorrências da lateral pós-vocálica

\begin{tabular}{lcc}
\hline Variável dependente & Apl./Total & \% \\
\hline Manutenção do [^] & $754 / 1184$ & 64 \\
\hline Vocalização [w] & $351 / 1184$ & 29 \\
\hline Apagamento [ Ø] & $79 / 1184$ & 7 \\
\hline
\end{tabular}

Fonte: Silva; Lucena, 2015.

Os dados gerais indicaram a ocorrência de um processo de acomodação em andamento, tendo em vista que, mesmo sendo a lateral velarizada a forma de produção predominante nas variedades africanas em questão, quase um terço do total de laterais pós-vocálicas produzidas pelos entrevistados foram realizadas à maneira do português brasileiro.

As variáveis "país de origem" e "tempo de exposição", nessa ordem, foram consideradas as mais relevantes do ponto de vista estatístico para o fenômeno em ambas as rodadas do software.

Tabela 2. Influência da variável país de origem na vocalização $[\mathrm{w}]$ da lateral

\begin{tabular}{lccc}
\hline País de origem & Apl./Total & \% & P.R. \\
\hline Cabo Verde & $247 / 518$ & 47,7 & 0,842 \\
\hline Guiné-Bissau & $104 / 666$ & 15,6 & 0,214 \\
\hline
\end{tabular}

Input: 0,207; Significância: 0,008

Fonte: Silva; Lucena, 2015. 
Uma possível explicação para os dados tão contrastantes em relação aos indivíduos dos dois países diz respeito à formação histórica dessas duas nações, e às decorrentes relações de identificação e pertencimento com as quais esses informantes se relacionam com seus países de origem. A nação cabo-verdiana, desde a sua formação, foi marcada por rupturas e hibridizações de culturas, tendo em vista ter sido formada por diversas etnias da África continental e por colonizadores portugueses (LEWIS; SIMONS; FENNING, 2013), o que não aconteceu na GuinéBissau. No entanto, o que é importante destacar aqui é que os dados estatísticos não parecem ser suficientes para explicar o comportamento linguístico dos informantes.

Silva e Lucena (2015) se questionaram sobre a possibilidade de a variável tempo de exposição estar exercendo algum tipo de influência no comportamento linguístico dos falantes. Esta foi a segunda variável mais importante selecionada pelo programa, tanto na aplicação do [w] quanto na aplicação do [1]. Para sanarmos a dúvida, procuramos estabelecer um paralelo das duas variáveis com o número de informantes:

Quadro 1. Mapeamento das variáveis país de origem, tempo de exposição e número de informantes

\begin{tabular}{|l|l|c|}
\hline País de origem & Tempo de exposição & No de informantes \\
\hline \multirow{4}{*}{ Cabo Verde } & Menor que 3 anos & 1 \\
\cline { 2 - 3 } & Entre 3 e 8 anos & 2 \\
\cline { 2 - 3 } & Maior que 8 anos & - \\
\hline \multirow{4}{*}{ Guiné-Bissau } & Menor que 3 anos & 1 \\
\cline { 2 - 3 } & Entre 3 e 8 anos & 1 \\
\cline { 2 - 3 } & Maior que 8 anos & 2 \\
\hline
\end{tabular}

Fonte: Silva; Lucena, 2015.

O que se percebe pelo quadro acima é que se o tempo ao qual os informantes estiveram expostos ao novo dialeto estivesse de fato influenciando os dados referentes à análise da variável país de origem, o resultado teria sido exatamente o inverso, tendo em vista que os informantes cabo-verdianos (os que mais acomodaram), de um modo geral, estão sujeitos a um tempo de exposição menor que os informantes guineenses. 
Nesse sentido, faz-se oportuna a avaliação dos aspectos qualitativos acerca da atitude dos informantes com relação aos seus países de origem e o Brasil. Acreditamos que apenas a partir de um cruzamento dos dados estatísticos com uma análise mais qualitativa do fenômeno é que se podem fornecer respostas mais conclusivas sobre o comportamento linguístico dos falantes. É exatamente dentro dessa discussão que se insere este artigo.

Destacamos, portanto, trechos das entrevistas que fizessem referências às atitudes linguísticas dos falantes, e fizemos uma comparação com o índice de acomodação dialetal de cada informante, exposto na tabela 3, e suas características sociais, expostas no quadro 2 :

Tabela 3. Percentual de acomodação dialetal por informante

\begin{tabular}{ccc}
\hline Informante & Apl./Total & $\%$ \\
\hline 1 & $48 / 161$ & 29,8 \\
\hline 2 & $46 / 185$ & 24,9 \\
\hline 3 & $153 / 172$ & 89,0 \\
\hline 4 & $7 / 166$ & 4,2 \\
\hline 5 & $73 / 181$ & 40,3 \\
\hline 6 & $8 / 152$ & 5,3 \\
\hline 7 & $16 / 167$ & 9,6
\end{tabular}

Input: 0,206; Significância: 0,000

Fonte: Silva; Lucena, 2015.

Quadro 2. Características sociais dos informantes

\begin{tabular}{|c|c|c|}
\hline Informante & País de origem & Tempo de exposição \\
\hline 1 & Cabo Verde & 05 anos \\
\hline 2 & Cabo Verde & 08 meses \\
\hline 3 & Cabo Verde & 05 anos \\
\hline 4 & Guiné-Bissau & 01 ano \\
\hline 5 & Guiné-Bissau & 08 anos \\
\hline 6 & Guiné-Bissau & 06 anos \\
\hline 7 & Guiné-Bissau & 10 anos \\
\hline
\end{tabular}

Fonte: Silva; Lucena, 2015. 
O informante 3 é de Cabo Verde e, à época da entrevista, residia em João Pessoa há cinco anos e dez meses. Foi o informante que apresentou o maior índice de acomodação dialetal, com $89 \%$. Por meio da entrevista, pudemos perceber que ele faz uma boa avaliação a respeito do Brasil, demonstrando até mesmo desejo de permanecer aqui após seu período de estudos.

Apresentamos abaixo o trecho da entrevista que surgiu após ser questionado se tinha alguma preferência entre os dois dialetos. Ele começa falando que gosta da variedade brasileira, porém prefere a do sul do país, e depois passa a comparar o português brasileiro com o cabo-verdiano.

\section{(...) Aí eu acho que se perguntar assim: 'tu prefere um ou outro? Qual?' Aqui eu prefiro logo o... logicamente esse aqui, mas lá eu prefiro o outro. (Informante 3)}

Ressaltamos que o informante 3 foi o único que considerou aspectos de adequação ao contexto em seus comentários. Os outros informantes, ao serem questionados sobre qual variedade preferiam, escolheram o português europeu, justificando a escolha com argumentos que envolvem pureza e correção linguística.

Por outro lado, analisando a entrevista do informante 4, guineense, e que apresentou o menor índice de acomodação dentre todos $(4,2 \%)$, encontramos uma maior valorização da sua nação e cultura, manifestada também no forte desejo de retornar ao país, levando consigo o aprendizado dos anos de estudo no Brasil, a fim de contribuir com o desenvolvimento da sua nação de origem.

Mostramos a seguir dois trechos da entrevista do informante 4, em que menciona o desejo de retornar à GuinéBissau. O primeiro trecho refere-se ao momento em que foi perguntado onde gostaria de morar, e o segundo refere-se a quando foi perguntado como se imaginava daqui a vinte anos.

\footnotetext{
De preferência no meu país. Eu quero morar no meu país. Trabalhar no meu país. (Informante 4)
} 


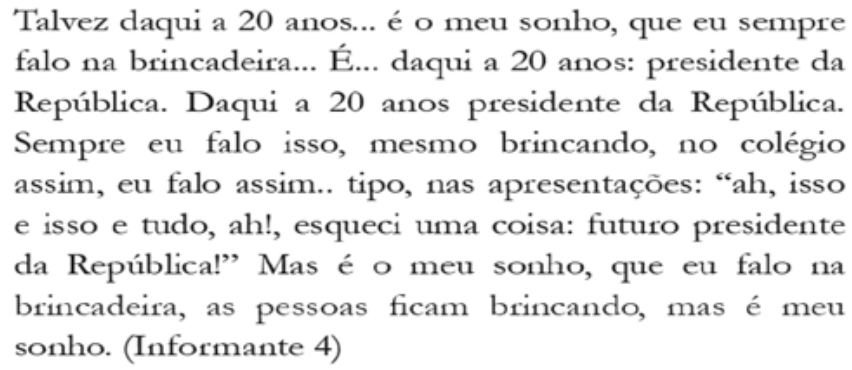

Oinformante 4, além de manifestar objetivamente o desejo de morar e trabalhar em seu país de origem, demonstra ter grandes planos para sua vida futura lá, pretendendo vir a ser, inclusive, presidente da República. Tal declaração revela interesse por parte do informante em dedicar parte de sua vida à gerência do país, constituindo-se em seu principal projeto de vida futuro. Além disso, imaginamos que um representante de Estado busque manter preservada e aparente a sua identidade nacional, para que provoque no povo o sentimento de representatividade esperado para tal função. Essas questões podem ter contribuído para o alto índice de resistência linguística que o informante apresenta para preservar sua variedade de origem.

Como podemos perceber pelos trechos acima, apenas a partir de uma análise qualitativa das atitudes linguísticas dos informantes é que podemos corroborar ou refutar os dados apontados pelo levantamento estatístico, o que confirma nossa preocupação em insistir nesse tipo de análise.

A seguir, observaremos que os dados estatísticos per se podem nos levar a conclusões equivocadas a respeito do fenômeno da acomodação dialetal. A variável "tempo de exposição" foi a segunda mais relevante para o fenômeno da manutenção da lateral velarizada, conforme a tabela 4 :

Tabela 4. Influência da variável tempo de exposição na vocalização da lateral

\begin{tabular}{lccc}
\hline Tempo de exposição & Apl./Total & \% & P.R. \\
\hline Menor que 3 anos & $53 / 351$ & 15,1 & 0,183 \\
\hline Entre 3 e 8 anos & $209 / 485$ & 43,1 & 0,495 \\
\hline Maior que 8 anos & $89 / 348$ & 25,6 & 0,823 \\
\hline
\end{tabular}

Input: 0,207; Significância: 0,008

Fonte: Silva; Lucena, 2015. 
Um rápido olhar pelos números apontados na tabela 4 pode nos levar à falsa impressão de que a variável tempo de exposição tem um fator preponderante na acomodação linguística dos falantes. Parece haver um continuum de acomodação nos dados de peso relativo (P.R.) (embora os dados percentuais não corroborem esse dado), fazendo com que falantes com menor exposição ao novo dialeto vocalizem menos e, portanto, mantenham o falar materno.

Voltando nosso olhar ao quadro 1, exposto anteriormente, observamos que não há, na pesquisa realizada, informantes oriundos de Cabo Verde com mais de oito anos de vivência na Paraíba. Como já foi demonstrado anteriormente, os guineenses são mais resistentes ao processo de acomodação. Por serem os únicos na categoria maior que oito anos, podem estar enviesando a progressão linear típica encontrada na variável tempo de exposição. É possível que em uma pesquisa onde fossem considerados apenas os informantes cabo-verdianos, ou que houvesse igualdade numérica entre os informantes cabo-verdianos e guineenses em cada categoria, a progressão linear de acomodação esperada fosse encontrada.

Mas a explicação não parece ser apenas esta. Os dados estatísticos só podem ser compreendidos a partir de uma análise qualitativa. Só assim é possível jogar alguma luz no fenômeno de acomodação dialetal. Analisando as apreciações linguísticas dos informantes obtidas no "módulo língua" da entrevista, encontramos que a impressão geral que eles têm do português brasileiro é negativa.

Agora eu disse 'aí..' 'aí...' não tem lá em Cabo Verde, né? 'Né, tá vendo? São algumas coisas que sem querer eu já não consigo evitar isso, né? Mas é assim, não é que eu to, é... rebaixando o português de vocês, mas é assim: eu tento não usar esses $\{$ init\}, porque eu sei que o português de Portugal é um português padrão, um português assim conhecido no mundo todo, diferente do português do Brasil, que é aqui no Brasil. (Informante 2) 
Ham ram. Eu acho... acabo utilizando... agora eu nem sei avaliar o meu português. <Sei.> Se eu tol falando um português de antes que eu falava, tipo um português que eu falava d'antes, que é um pouco puro, né? 'Tipo, português mais ligado ao de Portugal, e agora um português... eu não sei diferenciar agora. < Sei. > Sei não. (Informante 4)

Os trechos transcritos acima demonstram a força que o processo colonizador ainda exerce sobre os colonizados. A língua do colonizador é por eles considerada a modalidade superior e é referida como o padrão, a língua pura, a língua correta. Essa hierarquização é recorrente e aparece em quase todas as falas coletadas. Parece indicar uma naturalização da superioridade do colonizador e de sua cultura, em contraponto às modalidades culturais e linguísticas consideradas inferiores, híbridas, impuras.

Assim, há indicações nas falas dos entrevistados da presença de um princípio de classificação que hierarquiza as línguas. É em referência à língua do colonizador europeu que elas são classificadas e hierarquizadas e as mais próximas daquela são consideradas mais bonitas, mais suaves, mais corretas e mais puras do que as que dela se distanciam.

A partir dessas novas informações a respeito das atitudes linguísticas dos falantes é que podemos repensar o peso do tempo de exposição nos fenômenos de acomodação dialetal e explicar a não perfeição do continuum apresentado na tabela 4. Daí a importância desse tipo de análise.

Questionamos ainda os informantes sobre as diferenças dialetais entre as variedades brasileiras, e o que encontramos em cinco das sete respostas foi uma preferência pelas variedades do sul e sudeste do país, em detrimento das variedades do nordeste (entre as quais o português de João Pessoa se insere).

Olha, eu acho que fala do paraibano é um pouco mais desligada aí do português de Portugal. Acredito que o falar das pessoas do Brasil lá do sul é mais correto do que aqui. (...) aqui no João Pessoa é, eu posso dizer assim que o português dele já é muito mais ainda ruim do que... não é que é ruim, né? $\mathrm{Ok}$, não é ruim. Mas assim, é mais assim num nível mais baixo ainda do que nas pessoas da zona sul. Eu acho que é um pouquinho mais baixo. (Informante 2) 
De um modo geral, todas as comparações analisadas acima indicam que atributos linguísticos positivos, como bonito, correto ou puro, foram sempre relacionados às variedades social e historicamente mais poderosas.

Assim, o que se pode depreender da pesquisa, no recorte que nos interessa neste artigo, é que, apesar de a variável tempo de exposição exercer uma influência no processo de acomodação dialetal, ela necessita de um gatilho para o seu funcionamento: a presença de atitudes linguísticas favoráveis com relação ao novo dialeto a ser adquirido.

\section{A acomodação dialetal do/s/ em coda silábica: estudo I}

Em 2013, Chacon e Lucena publicaram o estudo "Considerações sobre o processo de acomodação dialetal do/s/em coda silábica por falantes paulistas em João Pessoa" (CHACON; LUCENA, 2013). O objetivo da pesquisa foi analisar a acomodação dialetal de informantes provenientes da cidade de São Paulo que passaram a residir em João Pessoa. A ideia era de controlar o fenômeno da palatização das fricativas alveolares em coda medial diante de oclusivas dentais, tendo em vista que os dois dialetos possuem uma clara distinção com relação a esse segmento. No dialeto paulista, há uma tendência para a não palatalização (ex.: pa[s]ta, e[z]drúxula), enquanto que no dialeto pessoense há uma tendência contrária (ex.: pa[J]ta, e[3]drúxula).

A partir de um corpus formado por 10 informantes paulistas, residentes há pelo menos um ano em João Pessoa, foram realizadas as seguintes etapas: 1) uma "entrevista" sociolinguística nos moldes labovianos; 2) uma "entrevista" sobre o módulo língua; 3) uma leitura de textos (com 26 palavras com fenômeno).

Foram controladas as seguintes variáveis: a) estilo (entrevista e leitura de textos); b) tempo de exposição (1-3 anos de residência; entre 3 e 5 anos; mais de 8 anos); c) idade (de 19 a 25 anos; acima de 30 anos); d) naturalidade dos pais (falantes com pais do Sudeste do país; falantes com pais do Nordeste do país; falantes com pais do Nordeste e do Sudeste).

Para a análise quantitativa dos dados, foi usado o software Goldvarb X (SANKOFF; TAGLIAMONTE; SMITH, 2005), utilizado em pesquisas variacionistas. Foi obtido um total de 730 ocorrências da fricativa em posição de coda silábica, 
das quais 254 foram de aplicação do fenômeno da palatalização (com um percentual de 34,8\%) e 476 de não aplicação, resultando em $65,2 \%$ de não palatalização, ou seja, da não acomodação ao dialeto paraibano. Os fatores estatisticamente relevantes apontados pelo Goldvarb X foram: a) tempo de exposição; b) faixa etária e c) naturalidade dos pais.

Como podemos observar, também nesse estudo o fator tempo de exposição se mostrou de grande relevância para o fenômeno da acomodação dialetal, o que confirma nossas hipóteses. De fato, a primeira variável selecionada pelo programa foi o tempo de exposição ao novo dialeto, confirmando a hipótese de que quanto maior o período de contato com a nova variedade, maior a acomodação do falante.

Tabela 5. Acomodação relacionada ao tempo de exposição

\begin{tabular}{cccc}
\hline \multicolumn{4}{c}{ PALATALIZAÇÃO x TEMPO DE EXPOSIÇÃO } \\
\hline Fatores & Apl./Total & $\%$ & Peso Relativo \\
\hline (仑̂ de 8 ) & $221 / 481$ & 45,9 & 0,70 \\
\hline (3 a 5) & $23 / 118$ & 19,5 & 0,31 \\
\hline (1 a 3) & $10 / 131$ & 7,6 & 0,08 \\
\hline
\end{tabular}

Input: .28; Significância: .015

Fonte: Chacon; Lucena, 2013.

É possível observar na tabela 5 que os falantes paulistas que estão vivendo em João Pessoa há mais tempo, ou seja, acima de oito anos de exposição ao dialeto pessoense, são os que apresentaram um índice maior de palatalização da fricativa em posição de coda silábica (com peso relativo de 0,70 ).

Os resultados revelam um continuum de acomodação que está relacionado ao tempo de exposição dialetal $(0,08<0,31<$ 0,70), o que confirma a hipótese da influência desta variável para a acomodação dialetal, corroborando os resultados de outros trabalhos realizados, como os de Marques (2006) e Martins (2008). Os dados se revelaram surpreendentes se considerarmos que a pesquisa trabalhou com uma amostra de fala de informantes oriundos de uma comunidade de maior prestígio dialetal expostos a um dialeto de menor prestígio, o que pressupõe, segundo a literatura, dificuldade de acomodação. 
De fato, falantes de dialetos menos prestigiados acabam adquirindo aspectos do falar mais influente socialmente, fato que seria mais difícil de ocorrer na situação inversa.

No entanto, mais uma vez é preciso relativizar um pouco a influência da variável tempo de exposição a partir dos dados qualitativos coletados pela pesquisa. De fato, mais uma vez nos encontramos em uma posição em que é necessário analisar cada informante individualmente, para apontarmos tendências de maior acomodação ao novo dialeto. $\mathrm{O}$ que se pretende enfatizar aqui é que existe uma tendência de que a variável tempo de exposição seja uma grande catalizadora do fenômeno de uma maneira geral, no entanto, questões idiossincráticas podem retardar ou acelerar esse processo. Vejamos o quadro abaixo, para tirarmos algumas conclusões com base nos dados qualitativos.

Quadro 3. Percentual de palatalização por falante

\begin{tabular}{|c|c|c|}
\hline Informante & Tempo de exposição & $\begin{array}{c}\text { Percentual de } \\
\text { palatalização }\end{array}$ \\
\hline $\mathbf{1}$ & $\mathbf{1 6}$ anos & $\mathbf{1 9 . 8} \%$ \\
\hline $\mathbf{2}$ & $\mathbf{1 6}$ anos & $\mathbf{1 8 . 5 \%}$ \\
\hline 3 & 4 anos & $6.7 \%$ \\
\hline 4 & 15 anos & $9.1 \%$ \\
\hline 5 & 1 ano e 4 meses & $2.4 \%$ \\
\hline $\mathbf{6}$ & $\mathbf{1 0}$ anos & $\mathbf{2 2 . 1} \%$ \\
\hline 7 & 1 ano e 4 meses & $1.2 \%$ \\
\hline 8 & 11 anos & $6.0 \%$ \\
\hline 9 & 16 anos & $9.1 \%$ \\
\hline 10 & 4 anos & $5.1 \%$ \\
\hline
\end{tabular}

Fonte: Chacon; Lucena, 2013.

Observa-se no quadro 3 que os informantes 6, 1 e 2 foram os que mais se acomodaram ao novo dialeto, todos com porcentagem acima de $18 \%$. Observa-se, no entanto, que os falantes 4,9 e 8 (todos com tempo de exposição acima de 10 anos) apresentaram índices de palatalização bem diferentes. É 
importante tentar compreender esses resultados tão díspares como o falante 8 (com 11 anos de exposição ao novo dialeto, mas com índice de 6\%) e o falante 6 (com 10 anos de exposição e $22 \%$ de acomodação à palatalização).

Com base nos dados qualitativos da pesquisa, a partir da interpretação das atitudes linguísticas dos informantes, faz-se necessário relativizar a influência da variável tempo de exposição. O que se defende aqui é que o tempo de exposição é um fator relevante, mas que questões relacionadas à atitude linguística também exercem papel importante no processo e que juntos (longo tempo de exposição e atitude linguística positiva quanto ao novo dialeto) constituem um catalisador para o processo de acomodação dialetal. Vejamos as atitudes linguísticas desses falantes, para ilustrar melhor essa posição.

A informante 6 reside em João Pessoa há 10 anos e, quando questionada a respeito do falar pessoense, afirmou não ter incômodo com relação à nova variedade. Sugere-se, a partir de trechos de seu depoimento, que algum elemento subjetivo está presente que engatilha o processo de acomodação.

Eu acho que até mesmo pela questão do preconceito, você acaba tentando se moldar ao falar daqui, para você não [sofrer] tanto. Lá em casa, eu acho que quem mais sofreu fui eu, meus irmãos não. É tanto que você percebe bem claro o sotaque deles ainda. Quem mudou mais o sotaque lá em casa, fui eu. E eu acho que foi, porque eu fui quem sofri mais. Porque logo que eu cheguei aqui, era demais, todo mundo percebia, todo mundo falava do 'erre', a po[R]ta. Entendeu? Então, como isso me incomodava, então, eu comecei a mudar. (informante 6)

A informante 1 iniciou o contato dialetal muito cedo, aos três anos de idade. É filha de pai paulista e reside em João Pessoa há 16 anos. Quando questionada a respeito da sua opinião em relação ao dialeto paraibano, afirmou não ter qualquer desconforto.

Eu acho que a minha fala é mesmo, é daqui, é pessoense. Às vezes, eu até me espanto, que eu puxo muito mais o sotaque daqui. [Silêncio]. É, mas querendo ou não, meu sotaque é diferente, porque quando eu falo com o pessoal, eles acham diferente, ainda acham diferente. Então, meu sotaque não é daqui, e também não é de São Paulo. Mas eu acho que é mais puxado pro daqui.... Mas às vezes eu dou uma caidinha no de São Paulo, aí volto, aí vou de novo. (Informante 1) 
Por outro lado, a falante 5, com baixo índice de acomodação, é natural de Santos (SP). Ela declara peremptoriamente seu dissabor com o falar pessoense, e tem um posicionamento claro com relação às diferenças dialetais entre a fala local e de estados como o Rio de Janeiro e São Paulo. Ao ser perguntada sobre o falar pessoense, ela é enfática:

Eu acho muito feio, porque o pessoal fala cantando... É o jeito de falar cantando. [...] Ou tá falando ou tá cantando, é uma coisa ou outra. É um falar muito feio. [...] Eu não convivi com pessoas de outros lugares assim sabe, daqui, mas aqui de João Pessoa que eu conheço, é muito feio... É não gosto [risos]. (Informante 5)

Em alguns trechos de sua entrevista, é possível perceber claramente um policiamento no sentido de evitar qualquer possibilidade de acomodação dialetal, mantendo os traços do seu falar de origem por questões relacionadas a prestígio e poder, e que explica seu baixo índice de palatalização.

Eu me esforço tanto para não falar desse jeito (referindo-se ao falar pessoense), mas estou começando a falar [risos]. [...] Eu tiro até por mim, assim, que se eu chego falando paraibano o pessoal vai rir da minha cara... O pessoal da minha família mesmo vai começar a rir da minha cara, que eu tou falando paraibano que eu tou falando paraibano. Eu não tenho preconceito não, eu só acho feio [risos]. (Informante 5)

Como é possível observar, muitas questões atitudinais com relação às formas de falar podem acelerar ou retardar o processo de acomodação dialetal. Esse estudo de 2013 parece confirmar os dados mostrados na pesquisa realizada em 2015.

\section{A acomodação dialetal do/s/ em coda silábica: estudo II}

A última pesquisa que analisaremos aqui foi conduzida por Lima e Lucena e intitulada "Influência de variáveis não linguísticas no processo de acomodação dialetal do /s/ em coda silábica por paraibanos em Recife" (LIMA; LUCENA, 2013). Os autores analisaram a realização da fricativa alveolar /S/ em posição de coda silábica medial, devido ao fato de que esse segmento marca claramente a diferença entre os dialetos falados em João Pessoa (Paraíba) e em Recife (Pernambuco). De fato, diferentemente da capital paraibana, Recife apresenta 
a palatalização independente do contexto fonológico seguinte. Assim, é possível observar pronúncias como e[S]fera, ve[S]pa e $\mathrm{fu}\left[\int\right] \mathrm{ca}$ na capital pernambucana; em João Pessoa, as realizações comuns seriam e[s]fera, ve[s]pa e fu[s]ca.

O corpus utilizado na pesquisa foi constituído por 7 informantes paraibanos que residiam há no mínimo dois anos em Recife e foram realizadas as seguintes etapas: 1) uma "entrevista" sociolinguística nos moldes labovianos; 2) uma "entrevista" sobre o módulo língua; 3) uma leitura de textos (com 26 palavras com fenômeno).

Para a análise quantitativa dos dados, fez-se também uso do software Goldvarb X (SANKOFF, TAGLIAMONTE; SMITH, 2005). Foi obtido um total de 1.169 ocorrências, em que a forma palatalizada foi realizada 304 vezes contra 865 da não palatalização.

A palatalização em contexto diferente de $[t, d]$ foi observada em $26 \%$ das ocorrências, o que atestou a acomodação da fricativa coronal palatalizada por paraibanos que residem em Recife. Mesmo mostrando ainda uma tendência forte para a não palatalização ( $74 \%$ dos casos), a fala dos informantes mostrou que a convivência com o novo dialeto foi um gatilho para o processo de acomodação.

Como já apontado nos trabalhos resenhados acima, a variável selecionada como mais relevante estatisticamente foi o tempo de residência, o que corrobora a importância da influência do fator tempo de exposição nos fenômenos de acomodação dialetal. Vejamos os dados na tabela 6:

Tabela 6. Influência da variável "tempo de residência" na palatalização

\begin{tabular}{cccc}
\hline Fator & Apl./Total & \% & P.R. \\
\hline Até 3 anos & $45 / 922$ & 4 & 0,33 \\
\hline Após 10 anos & $306 / 812$ & 37 & 0,68 \\
\hline
\end{tabular}

Input: 0,117; Significância: 0,004

Fonte: Lima; Lucena, 2013.

Como é possível observar na Tabela 6, os dados parecem indicar um continuum de acomodação ao longo da exposição 
à nova forma linguística, produzindo uma espécie de interdialeto, que se diferencia ao mesmo tempo do dialeto de origem e do dialeto alvo.

Os dados quantitativos relacionados a cada um dos informantes também corroboraram a influência dessa variável. Como podemos observar na tabela 7 , os informantes que mais acomodaram foram os informantes 4 e 5 , que têm em comum o fato de morarem há mais de dez anos em Recife, além de terem uma atitude positiva em relação à nova realidade linguística, como veremos mais adiante.

Tabela 7. Palatalização dos informantes

\begin{tabular}{cccc}
\hline Fator & Apl./Total & \% & P.R. \\
\hline Informante 4 & $106 / 268$ & 39 & 0,72 \\
\hline Informante 5 & $157 / 397$ & 39 & 0,73 \\
\hline Informante 2 & $35 / 288$ & 12 & 0,34 \\
\hline Informante 6 & $6 / 216$ & 2 & 0,10 \\
\hline
\end{tabular}

Input: 0,208; Significância: 0,049

Fonte: Lima; Lucena, 2013.

Novamente chamamos a atenção para a necessidade de sondar as atitudes linguísticas dos falantes para corroborar ou refutar os dados apontados pela análise estatística. A informante 4, por exemplo, mora em Recife há mais de dez anos e foi casada com recifense. Ela apresentou uma acomodação dialetal bastante significativa: das 268 ocorrências da fricativa coronal em posição de coda, produziu a forma palatalizada 106 vezes, com um percentual de $39 \%$ dos casos.

Ao ser questionada a respeito da percepção das diferenças entre os dialetos, a informante demonstra conhecê-las, identificando a palatalização como uma dessas características. Ao mesmo tempo em que percebe a diferença, também identifica que acomodou essa característica linguística, tendo em vista que, ao retornar à Paraíba, as pessoas do seu ciclo de amizade percebem a diferença em seu falar. A informante consegue identificar a acomodação, definindo-a como algo espontâneo, efeito do entrosamento com as pessoas de Pernambuco: 
Com o tempo, com o passar do tempo, eu fui puxando esse [S]. Eu fui puxando esse [S] sem querer. Porque você vai se entrosando com as pessoas de lá. Então eu fui entrando na dança, como se diz, mas eu acho isso bom. (Informante 4)

Ela avalia o dialeto recifense como um falar "extrovertido", o que revela uma avaliação positiva a respeito da nova realidade linguística. Também tece comentários a respeito do comportamento dos falantes, avaliando-os como festivos. Esses posicionamentos são relevantes, pois nos levam a inferir que a avaliação positiva que o informante tem do recifense pode ser um dos fatores que propiciaram a acomodação ao novo dialeto.

É assim, bom, eu acho que é extrovertida, certo. Assim, apesar de ser assim, uma cidade grande, mas as pessoas são muito festeiras. Uma das diferenças do povo de lá e daqui é isso. Agora é que estão começando a ficar mais festivas as coisas aqui. João Pessoa, em relação à Recife, muitas vezes é cópia, né? Também, então assim, as pessoas de lá são muito festivas. (Informante 4)

A informante 5 mora em Recife há mais de dez anos, vive com dois filhos que nasceram na capital pernambucana e não retorna à Paraíba há muito tempo. Durante a entrevista, ela realizou 157 vezes a forma palatalizada, chegando a um peso relativo de 0,73 , fato que demonstra a acomodação ao falar recifense.

Bom, eu acho que eu falei aqui, eu não sei, eu tenho muito respeito por esse lugar, que eu me sinto bem e tou até hoje. Daí eu me sinto tão à vontade que eu acabo assimilando as coisas daqui. Eu gosto demais dessa terra, eu acho que esse foi um dos motivos, o outro motivo talvez até pra, pra gente conseguir se dar melho com as pessoas aqui. Então, a gente tem que, pronto, essa questão que eu falei, respeito, a gente tem respeito pela pessoa, tentar entender a pessoa e de repente a gente tá falando igual à pessoa, assimilando as coisas. (Informante 5)

Porém, mais uma vez chamamos a atenção para a necessidade de relativizarmos a importância da variável "tempo de residência" com base nos dados qualitativos. A informante 1, por exemplo, apesar de residir há mais de 10 anos em Recife, e ter contato diuturno com recifenses, não se acomodou à forma palatalizada em nenhum momento da entrevista. Os dados qualitativos parecem indicar que a atitude negativa exerce um papel bloqueador na influência do fator 
"tempo de residência". Assim, para que ele tenha um efeito catalisador da acomodação, o tempo de residência/exposição deve estar associado a uma avaliação positiva do novo falar.

É possível compreender, portanto, que posicionamentos particulares relativos à avaliação do novo dialeto e questões de atitude linguística em relação ao seu dialeto de origem contribuem para a preservação do falar. Logo, a análise dessas atitudes possui um peso grande para a interpretação do comportamento linguístico do participante e mostra que só é possível explicar o processo de acomodação dialetal por meio de um conjunto de fatores.

\section{Considerações finais}

Procuramos aqui oferecer uma visão panorâmica a respeito de três estudos que enfatizaram a análise da acomodação dialetal do ponto de vista quantitativo (a partir de uma proposta teórico-metodológica laboviana), juntamente com a análise de atitudes linguísticas. Nosso objetivo foi demonstrar que a simples análise estatística não parece ser suficiente para explicar o fenômeno da acomodação dialetal.

A primeira pesquisa analisada neste artigo foi relacionada à lateral em posição de coda silábica, que é produzida de maneira vocalizada no português brasileiro, em falantes provenientes de Cabo Verde e da Guiné Bissau. O segundo estudo observou o fenômeno da palatização das fricativas alveolares em coda medial diante de oclusivas dentais, ao analisar a fala de informantes paulistas que residiam em João Pessoa. O terceiro estudo tinha por foco a realização da fricativa alveolar /S/ em posição de coda silábica medial, em falantes paraibanos residindo em Recife (Pernambuco).

Como se observou nos três trabalhos, a variável tempo de exposição/tempo de residência se mostrou como a mais relevante nos fenômenos de acomodação dialetal. No entanto, algumas inconsistências nos dados quantitativos fizeram com que fosse necessário um olhar mais cuidadoso na análise das atitudes linguísticas dos falantes. Como mencionamos anteriormente, tudo parece indicar que atitudes negativas exercem um papel bloqueador na influência do fator tempo de residência/tempo de exposição. Para que essa variável se imponha como catalisadora da acomodação dialetal, o tempo 
de residência/exposição deve estar associado a uma avaliação positiva do novo falar.

Embora uma análise quantitativa nos forneça informações importantes para compreender os meandros dos fenômenos de contato linguístico, os estudos resenhados aqui parecem apontar para uma necessidade cada vez mais premente de uma análise qualitativa para a compreensão dos processos de acomodação dialetal.

\section{REFERÊNCIAS}

CARDOSO, Denise P. Atitudes linguísticas e avaliações subjetivas de alguns dialetos brasileiros. São Paulo: Blucher, 2015.

CHACON, Karoline de A.; LUCENA, Rubens M. Considerações sobre o processo de acomodação dialetal do /s/ em coda silábica por falantes paulistas em João Pessoa. In: ARNOUX, Elvira N.; ROCA, María del Pilar (Eds.). Del español y el portugués. João Pessoa: Editora da UFPB, 2013.

GILES, Howard. Accent mobility: a model and some data. Anthropological Linguistics. Bloomington, v.15, n. 2, p. 87-105, Feb. 1973.

GILES, Howard; COUPLAND, Justine; COUPLAND, Howard. Accomodation theory: communication, context and consequence. Cambridge: Cambridge University Press, 1987.

LABOV, William. The social stratification of English in New York City. Washington: Center of Applied Linguistics, 1966. Sociolinguistic patterns. Oxford: Basil Blackwell, 1972.

LAMBERT, William W.; LAMBERT, Wallace E. Psicologia social. Rio de Janeiro, Zahar, 1975.

LEWIS, M. Paul; SIMONS, Gary F.; FENNING, Charles D (Eds.). Ethnologue: Languages of the World. $17^{\mathrm{a}} \mathrm{ed}$. Texas: SIL International, 2013.

LIMA, Izete de Souza; LUCENA, Rubens M. Influência de variáveis não linguísticas no processo de acomodação dialetal do /s/ em coda silábica por paraibanos em Recife. Letrônica, Porto Alegre, v. 6, n. 1, p. 161-178, jan./jun. 2013.

MARQUES, Sandra Maria Oliveira. As vogais medias pretônicas em situação de contato dialetal. 2006. 159 f. Tese (Doutorado em Língua Portuguesa). Faculdade de Letras, Universidade Federal do Rio de Janeiro, Rio de Janeiro, 2006. 
MARTINS, Mariana de Souza. A palatalização de oclusivas dentais em contato dialetal. 2008. 145f. Dissertação (Mestrado em Linguística). Universidade Federal do Rio de Janeiro, Rio de Janeiro, 2008.

ROKEACH, Milton. Naturaleza de las actitudes. In: SILLS, David L. (Ed.). Enciclopedia internacional de las ciencias sociales. v. I, Madrid: Aguilar, 1974. p. 14-21.

SANKOFF, David; TAGLIAMONTE, Sali; SMITH, Eric. Goldvarb $X$ : a variable rule application for Macintosh and Windows. Department of Linguistics, University of Toronto, 2005.

SILVA, Paloma Freire Q.; LUCENA, Rubens M. A lateral pósvocálica em contato dialetal: um estudo com africanos lusófonos na Paraíba. Revista da ABRALIN. v.14, n.1, p. 431-468, jan./jun. 2015.

\section{Abstract \\ A quantitative and qualitative perspective on the effect of the variable duration of exposure in linguistic accommodation phenomena}

This article aims to offer an overall view of three works on linguist contact conducted in Northeast Brazil, by discussing the relevance of exposure duration/length of residence variable in the processes of linguistic accommodation. The researches were carried out between 2013 and 2015 at the Federal University of Paraiba and are the results of Master's dissertations completed in the Postgraduate Program in Linguistics. Although they were focused on a quantitative-oriented analysis, based on a Labovian theoretical-methodological proposal, we emphasize here the need for a more qualitative approach, with an increased focus on the linguistic attitudes of the speakers. We therefore conclude that, despite the influence of the exposure duration variable on the linguistic accommodation process, a trigger is required in order to have its function: the existence of conducive linguistic attitudes towards the new dialect to be learned.

Keywords: Linguistic analysis and theory. Linguistic contact. Linguistic accommodation theory. 